\title{
TNFRSF17 Positive
}

National Cancer Institute

\section{Source}

National Cancer Institute. TNFRSF17 Positive. NCI Thesaurus. Code C128845.

Indicates that TNFRSF17 expression has been detected in a sample. 